\title{
Ecosystem Services and Preventive Medicine
}

\section{A Natural Connection}

Viniece L. Jennings, $\mathrm{PhD},{ }^{1}$ Claire K. Larson, MD, ${ }^{2}$ Lincoln R. Larson, $\mathrm{PhD}^{3}$

From the ${ }^{1}$ U.S. Department of Agriculture, Forest Service, Athens, Georgia; ${ }^{2}$ Department of Medicine, University of California-San Francisco, San Francisco, California; and ${ }^{3}$ Department of Parks, Recreation, and Tourism Management, Clemson University, Clemson, South Carolina

Address correspondence to: Viniece L. Jennings, PhD, U.S. Department of Agriculture Forest

Service-Southern Research Station, Integrating Human and Natural Systems, 320 Green Street, Athens GA 30602. E-mail vjennings02@fs.fed.us. 
Modern public health challenges require interdisciplinary solutions that integrate knowledge of human behavior and its complex relationship with the physical environment. Historically, this discourse was dominated by studies of hazards and other negative health consequences associated with human-environment interactions. However, growing evidence suggests that contact with green spaces (e.g., parks, forests, gardens) can be beneficial to physical and mental health. ${ }^{1}$ Despite these findings, integration of the natural environment into preventive medicine policy and practice has been slow. This is partly due to limited recognition of the multifaceted health benefits associated with green spaces and the challenge of characterizing and evaluating these benefits. Minimal dialogue across disciplines, especially between environmental and health professionals, has exacerbated the divide, ${ }^{2,3}$ further hindering nature-based health promotion. Many environmental and social scientists have embraced the concept of "ecosystem services" as a framework for understanding, evaluating, and communicating the contributions of ecosystems to human well-being. ${ }^{4}$ Ecosystem services describe nature's direct and indirect benefits to humans, including life-supporting ecological processes and provision of outdoor spaces that encourage active lifestyles, which support the prevention of diseases and other maladies. As these services have major implications for human health and well-being, ${ }^{5,6}$ the integration of ecosystem services and preventive medicine may be an important strategy for advancing health research, education, and practice.

Research from multiple fields of study suggests that contact with nature can be beneficial to public health and well-being. ${ }^{1,4,7}$ Though a recent literature review showed mixed observations with regard to green space and physical activity, ${ }^{1}$ many studies suggest that green spaces help promote active lifestyles. For example, a cross-sectional study among some of the nation's 
largest cities observed a positive relationship between park density (i.e., acres of parkland as a percentage of land area) and local levels of physical activity. ${ }^{8}$ Hence, many recommend exposure to green spaces as a pathway to reduce obesity and promote cardiovascular health. ${ }^{9}$ Although most healthcare providers acknowledge the importance of physical activity and often give general exercise prescriptions, the added benefits of outdoor exercise are not adequately recognized. A systematic review of physical activity research suggests that, compared with exercising indoors, outdoor exercise is more strongly associated with positive mental health. ${ }^{10}$ Other research has revealed lower incidence of depressive symptoms in neighborhoods with greater access to green space. ${ }^{11}$ By fostering social interactions and community attachment, public green space can also create a social environment that is conducive to health promotion. ${ }^{12}$ From these studies, one can infer that direct interaction with, or proximity to, natural environments represents an important strategy for proactively addressing a variety of health issues. Systematically accounting for nature's contributions at multiple scales can ensure that these benefits are widely acknowledged as an important aspect of preventive care across multiple disciplines. ${ }^{13}$

Ecosystem services can help bridge this gap by highlighting key ecological functions or processes and the outcomes they produce. The concept emerged in the environmental field as a way to account for nature's economic benefits (i.e., goods and services), ${ }^{14}$ and it was not explicitly designed to resonate with a medical community that generally focuses on clinical interventions. However, ecosystem services also provide a broader context for connecting the influence of the physical environment with health at both the individual and population level, making them very relevant in the field of preventive medicine. 
Multiple typologies of ecosystem services exist. Among these frameworks is the Common International Classification of Ecosystem Services (cices.eu/), which is based on the initial categories outlined in the Millennium Ecosystem Assessment Report. ${ }^{6}$ In the Common International Classification of Ecosystem Services, services are grouped into provisioning services (e.g., food, water, energy), regulation and maintenance services (e.g., climate regulation, air purification, flood protection, disease control), and cultural services (e.g., physical use, experiential use, educational and aesthetic values). These categories illustrate how the effects of ecosystem services on health and well-being extend beyond the benefits derived from personal use. Through its presence alone, green space can provide nutritious food sources (a provisioning service), help manage storm water runoff (a regulation and maintenance service), reduce air pollution $^{1}$ (a regulation and maintenance service), and support climate mitigation (a regulation and maintenance service). For example, a longitudinal study across 15 U.S. states suggests that the loss of tree cover was associated with excess mortality from cardiovascular and lowerrespiratory illnesses. ${ }^{15}$ Such research highlights the indirect health benefits that ecosystems provide, particularly in urban landscapes where natural land cover is often limited.

Cultural ecosystem services are particularly important in preventive medicine. These services often foster direct interactions with green spaces, including physically active outdoor recreation or restorative aesthetic experiences, which generate underestimated health benefits. ${ }^{5}$ In many cases, however, cultural services are poorly integrated into existing environmental management or public health frameworks because they extend beyond the boundaries of traditional ecological study and generate outcomes that are difficult to define, measure, and analyze. ${ }^{5}$ Investigations of 
ecosystem services are often limited to observational and cross-sectional study designs. ${ }^{1}$ The lack of robust trial-level data often induces skepticism among health practitioners, who are hesitant to endorse or prescribe nature-based interventions when correlational evidence is mixed and traditional alternatives exist. The health benefits of lifestyle changes, such as dietary modifications and physical activity, are widely recognized. However, a growing body of evidence suggests that outdoor recreation and time in nature are similarly important for health promotion, but are rarely recommended by healthcare professionals. Recent research demonstrates tangible relationships between ecosystem services and human health in a way that enhances understanding and appreciation of nature's health benefits. ${ }^{16,17}$ As the state of knowledge progresses, health professionals currently recommending lifestyle changes such as dietary modifications and physical activity to address chronic health problems may begin to consider outdoor recreation and time in nature as potential remedies as well.

Improved capacity to account for the role of ecosystem services has important implications for public health. For example, the subdiscipline of "public health ecology" recognizes that ecosystem integrity and health promotion are inextricably linked through the natural and built environments. ${ }^{18}$ To illustrate this explicit link, a novel U.S. Environmental Protection Agency tool known as the Eco-health Relationship Browser illustrates the linkages between ecosystem services and different domains of human health. ${ }^{19}$ The information that supports this tool was retrieved from a systematic review of more than 300 research articles examining links between ecosystem services and public health. ${ }^{20}$ Other research has explored "dose-response" relationships to illustrate the effect of different doses of nature on various health indicators. ${ }^{3}$ Such inquiries can provide more insight about underlying pathways needed to support a causal 
relationship and the levels of various ecosystem services required to achieve health goals. An ecosystem services perspective can also inform strategies for identifying and addressing health disparities among income and racial/ethnic groups. Studies indicate that enhanced contact with urban green space may be particularly important among racial/ethnic minority and low-income populations at high risk of developing health problems such as obesity, cardiovascular disease, and heat-related illnesses. ${ }^{17,21}$

Building on these initiatives, a more intentional integration of ecosystem services into preventive medicine would augment standard medical practices and improve human health and well-being, while simultaneously conserving natural environments. Although some integration has started to occur, ${ }^{13}$ strategically focusing future efforts could expedite this process. This can be accomplished in the following ways:

1. enhanced transdisciplinary communication using ecosystem services as an avenue to describe environmental benefits (and disservices to articulate negative health implications);

2. clarification of the effects of contact with the physical environment for healthcare providers, focusing on both physical and mental health outcomes;

3. increased funding to support interdisciplinary research on the relationships between ecosystem services and public health;

4. expanding the scope of public health journals and conferences to solicit studies with an ecosystem services perspective; and

5. training for healthcare providers and public health officials that explicitly acknowledges the health outcomes associated with ecosystem services. 
Some programs are already making strides by establishing mutually beneficial partnerships between environmental and health care professionals. One example is the Park Prescription Program, a new initiative that is gaining traction across the U.S., involving organizations such as the National Park Service, CDC, medical practitioners, and insurance providers. ${ }^{22}$ By connecting residents with local green spaces and recreation opportunities, this program helps providers promote active lifestyles across diverse patient populations. This preventive approach benefits: medical practitioners, who are better able to address the health problems of their patients; patients, who can enjoy the benefits of improved physical and mental health; and insurance providers, who have lower costs associated with medical interventions for and complications of chronic disease. ${ }^{22}$ The program also promotes outdoor recreation, which helps participants develop stronger attachments to green spaces and the unique services they provide. Perhaps an ecosystem services framework would assist health professionals to develop similar programs and generate program support by highlighting the full range of benefits that nature provides to individual and population health.

The new frontier in public health centers on the intersection of ecological, physical, and socioeconomic worlds - nexus that is particularly complex in urban areas. Such complexity necessitates creative solutions that span disciplinary boundaries. Infusing the concept of ecosystem services into the dialogue surrounding nature and health can help address existing barriers. Although this paradigm shift could influence many facets of health care, preventive medicine - particularly the specialty of public health and general preventive medicine-is uniquely positioned to pioneer the movement to incorporate ecosystem services into the health 
sector. By understanding and leveraging the unique assets that ecosystems provide, preventive medicine scholars and practitioners will be better positioned to respond to contemporary health challenges. Progress will continue with improved strategies for quantifying the types and levels of ecosystem services needed to address particular health conditions along with facilitating equitable distribution of ecosystem services across all populations. An innovative new destination in public health scholarship and practice could be achieved by building on the foundation of ecosystem services — one interdisciplinary bridge at a time. That's a natural connection that should not be ignored. 


\section{Acknowledgments}

This project is supported by an agreement (JV-11330144-060) funded by the U.S. Department of Agriculture Forest Service. The authors would also like to thank Dr. Myron Floyd whose review advanced the concepts expressed in this manuscript.

The perspective in this article are those of the authors and do not necessarily reflect the view of the Forest Service or U.S. Department of Agriculture.

No financial disclosures were reported by the authors of this paper. 


\section{References}

1. Hartig T, Mitchell R, de Vries S, Frumkin H. Nature and Health. Annu Rev Public Health. 2014;35(1). http://dx.doi.org/10.1146/annurev-publhealth-032013-182443.

2. Karjalainen E, Sarjala T, Raitio H. Promoting human health through forests: overview and major challenges. Environ Health Prev Med. 2010;15(1):1-8. http://dx.doi.org/10.1007/s12199-008-0069-2

3. Shanahan DF, Fuller RA, Bush R, Lin BB, Gaston KJ. The health benefits of urban nature: How much do we need? BioSci. 2015;65(5):476-485. http://dx.doi.org/10.1093/biosci/biv032.

4. Elmqvist T, Setala H, Handel SN, et al. Benefits of restoring ecosystem services in urban areas. Curr Opin Environ Sustain. 2015;14:101-108. http://dx.doi.org/10.1016/j.cosust.2015.05.001.

5. Daniel TC, Muhar A, Arnberger A, et al. Contributions of cultural services to the ecosystem services agenda. Proc Natl Acad Sci USA. 2012;109(23):8812-8819. http://dx.doi.org/10.1073/pnas.1114773109.

6. WHO. Ecosystems and Human Well-Being-Health Synthesis: a report of the Millennium Ecosystem Assessment. Geneva, Switzerland: WHO; 2005.

7. Wolf KL, Robbins A. Metro nature, environmental health, and economic value. Environ Health Persp. 2015;123(5):390-398. http://dx.doi.org/10.1289/ehp.1408216.

8. West ST, Shores KA, Mudd LM. Association of available parkland, physical activity, and overweight in American's largest cities. J Public Health Manag Pract. 2012;18(5):423430. http://dx.doi.org/10.1097/PHH.0b013e318238ea27. 
9. Sallis JF, Floyd MF, Rodríguez DA, Saelens BE. Role of built environments in physical activity, obesity, and cardiovascular disease. Circulation. 2012;125(5):729-737. http://dx.doi.org/10.1161/CIRCULATIONAHA.110.969022.

10. Thompson Coon J, Boddy K, Stein K, Whear R, Barton J, Depledge MH. Does participating in physical activity in outdoor natural environments have a greater effect on physical and mental wellbeing than physical activity indoors? A systematic review. Environ Science Technol. 2011;45:1761-1772. http://dx.doi.org/10.1021/es102947t.

11. Miles R, Coutts C, Mohamadi A. Neighborhood urban form, social environment, and depression. J Urban Health. 2011;89(1):1-18. http://dx.doi.org/10.1007/s11524-0119621-2.

12. Fan Y, Das KV, Chen Q. Neighborhood green, social support, physical activity, and stress: Assessing the cumulative impact. Health Place. 2011;17:1202-1211. http://dx.doi.org/10.1016/j.healthplace.2011.08.008.

13. Gentry BS, Anderson JE, Krause DR, Tucker WC, Tuddenham KA. Improving human health by increasing access to natural areas: Linking research to action at scale (Report of the 2014 Berkeley Workshop). New Haven, CT: Yale School of Forestry \& Environmental Studies; 2015.

14. Costanza R, de Groot R, Sutton P, et al. Changes in the global value of ecosystem services. Glob Environ Change. 2014;26:152-158. http://dx.doi.org/10.1016/j.gloenvcha.2014.04.002.

15. Donovan GH, Butry DT, Michael YL, et al. The relationship between trees and human health: Evidence from the spread of the Emerald Ash Borer. Am J Prev Med. 2013;44(2):139-145. http://dx.doi.org/10.1016/j.amepre.2012.09.066. 
16. Myers S, Gaffikin L, Golden C, et al. Human health impacts of ecosystem alteration. Proc Natl Acad Sci USA. 2013;110(47):18753-18760. http://dx.doi.org/10.1073/pnas.1218656110.

17. Jennings V, Johnson Gaither C. Approaching Environmental Health Disparities and Green Spaces: An Ecosystem Services Perspective. Int J Env Res Public Health. 2015;12(2):1952-1968. http://dx.doi.org/10.3390/ijerph120201952.

18. Coutts C. Public Health Ecology. J Environ Health. 2010;72(6):53-55.

19. U.S. Environmental Protection Agency. Eco-Health Relationship Browser 2014; http://enviroatlas.epa.gov/enviroatlas/Tools/EcoHealth_RelationshipBrowser/introduction .html. Accessed July 20, 2015.

20. Jackson L, Daniel J, McCorkle B, Sears A, Bush K. Linking ecosystem services and human health: the Eco-Health Relationship Browser. Int J Public Health. 2013;58(5):747-755. http://dx.doi.org/10.1007/s00038-013-0482-1.

21. Mitchell R, Popham F. Effect of exposure to natural environment on health inequalities: an observational population study. The Lancet. 2008;372(9650):1655-1660. http://dx.doi.org/10.1016/S0140-6736(08)61689-X.

22. Institute at the Golden Gate. Park prescriptions: Profiles and resources for good health from the great outdoors. 2010; www.parksconservancy.org/assets/programs/igg/pdfs/park-prescriptions-2010.pdf. 